\title{
STAKEHOLDERS' PREFERENCES ASSESSMENT TOWARD SUSTAINABLE SANITATION STRATEGY - AN APPLICATION OF THE ANALYTIC HIERARCHY PROCESS
}

\author{
Pham Ngoc BAO* \\ Center for Sustainable Development Studies; \\ Toyo University; 2-36-5 Hakusan, Bunkyo-ku, Tokyo 112-0001, Japan. \\ E-mail: bao@toyo.jp; baodhxd@yahoo.com \\ Toshiya ARAMAKI \\ Department of Regional Development Studies; \\ Toyo University; 2-36-5 Hakusan, Bunkyo-ku, Tokyo, Japan \\ Keisuke HANAKI \\ Department of Urban Engineering - The University of Tokyo; \\ 7-3-1 Hongo, Bunkyo-ku, Tokyo, Japan.
}

\begin{abstract}
Decision making in sanitation planning is often complex, with inherent trade-offs among sociopolitical, environmental, technical, and economic factors. The selection of appropriate and sustainable sanitation systems for municipal wastewater treatment involves multiple criteria with conflicting stakeholder preferences. To fulfill conflicting yet complementary objectives, a system analysis technique called the Analytic Hierarchy Process (AHP) has been employed as a decision support tool to aid decision makers in sanitation planning process in developing countries. AHP- in combination with life cycle assessment (LCA) and a proposed set of multi-dimensional criteria-has worked as an effective decision support tool for the sustainability assessment and selection of appropriate wastewater treatment system with a capacity of $1200 \mathrm{~m} 3 / \mathrm{d}$, in a case study in Toan Thang, a small town in Vietnam. A shortlist of three selected strategies and a set of impact categories (also referred to as assessment criteria) make up a complex decision-making process involving 109 stakeholders, categorized into three different groups: sanitation scientists, engineers, and consultants (SG1); policy decision makers from government (SG2); and local town residents and interest groups (SG3). The characterization of each strategy is based on a series of impact categories and life cycle assessments addressing social, economic, health, technical and functional, and environmental aspects. Results from this case study have clearly indicated that the public's understanding of tradeoffs is critical in gaining public support for long-term sustainability of the solution. The findings from this study have validated AHP as an effective and flexible communication tool for group decision making in sanitation planning.
\end{abstract}

Keywords: Analytic hierarchy process; assessment criteria; sanitation planning; stakeholders' preferences; wastewater treatment.

\section{Introduction}

The impacts from the discharge of domestic wastewater into rivers, lakes, estuaries, and the sea is a matter of great concern in most developing countries, especially in a country like Vietnam. By one estimate, as much as two-thirds of the wastewater generated in the world receives no treatment (Mariño and Boland 1999). Besides, inappropriate treatment levels or technologies have often been selected, leading to ineffective solutions, excess costs, or disappointing results (Mariño and Boland 1999). The consequences of these failures are serious environmental and human health problems. Two main reasons for such problems are lack of or insufficient involvements of both governmental and non-governmental stakeholders at the early stage

\footnotetext{
${ }^{*}$ Corresponding author
} 
of the sanitation planning process and high mitigation costs of advanced technologies, which are often imported from developed countries.

Several participatory methods including public telephone or e-mail surveys, community workshops, public meetings and discussion with community leaders, and opportunities for public comments have been used. They are sometimes criticized as inadequate, as merely information-gathering exercises, so that stakeholders have little direct role in identifying issues, developing alternative management options, or prioritizing choices (Herath 2004).

In this paper, the analytic hierarchical process (AHP) technique was adopted in trade-off considerations among assessment criteria and stakeholder groups' preferences with respect to the selection of appropriate and sustainable wastewater treatment strategies for small towns of Vietnam. AHP is a quantitative technique that structures a multi-attribute, multi-person, and multi-period problem hierarchically to facilitate solutions (Liu et al. 2005). It allows stakeholders directly involve in identifying issues and developing alternative management options that are appropriate and sustainable under their local context. Consequently, valuable information could be obtained about stakeholders' preferences and their effects on the choice of strategy as well as about possibilities to attain a compromise on their strongly conflicting preferences.

\section{Investigated area and study methods}

\subsection{Current situation on wastewater treatment and management in small towns of Vietnam}

Small towns in Vietnam comprise a) small towns (population between 4000 and 30000 ), and b) townlets (3 000 countrywide, with a minimum population of 2000 ). The total population in small towns and townlets is 15 million (about 22\% of total population) (Staykova and Kingdom 2006). Small towns are often situated between the urban and the rural in many ways-institutionally, financially, and legally. However, small towns do not completely fit within either the urban or rural context. They are often considered too small to be managed institutionally and too big for effective community management.

A typical small town of Toan Thang has been selected as a case study to test our proposed approach. Toan Thang commune is located in the north of Kim Dong district, Hung Yen province, Vietnam. The commune is divided into 4 villages, including Truong Xa, Nghia Giang, Dong An, and An Xa. Total natural land area of the commune is 725.8 ha, of which 440 ha is used for rice farming. Average agricultural land area per capita is $429 \mathrm{~m}^{2}$, less than half the national level. Most of the commune land area is in the lowland. There are 2 rivers running across the commune, namley Kim Nguu and Dien Bien River, which have been heavily polluted by domestic wastewater, and currently cannot be used as a water source for domestic use. Total population of the town is 10236 people with 2645 households. From the statistical data of the town, it is expected that the population will increase to 23000 people by the year 2025 (Viwase 2007a). Revenue of Toan Thang commune is mainly come from agricultural production, accounting for $45 \%$ of total revenue. Average per capita income is increasing every year; in 2004, average per capita income reached 4.7 million VND per capita per year (1 USD is equivalent to $16000 \mathrm{VND}$ ); in 2005, 5.8 million VND per capita per year; and in 2006, 6.5 million VND per capita per year (Viwase 2007b).

Concerning the status of water use and environmental sanitation, according to the results from field observation and surveys conducted during the summers of 2007 and 2008, local people currently use three sources of water for cooking, drinking and domestic purposes: rainwater, drilled well water, and hand-dug well water simultaneously. However, the use of hand-dug well is reducing and mainly poor households use this source of water. Drilled well water and hand-dug well water have a fishy smell and turn yellow and salty after a few minutes. Regarding the on-site sanitation facilities, the survey revealed that $58 \%$ of households in Toan Thang use septic tank and semi-septic tank toilets, $20 \%$ use double vault compost latrines, $18 \%$ use single vault compost latrines and the remaining use flushing toilets without septic tanks. The simple and incomplete sewerage system is often used concurrently for rainwater, wastewater and livestock wastewater disposal. There is no proper wastewater collection and treatment system in small towns. Most wastewater generated runs into side drains or absorbs into ponds, rivers, or soil. According to Viwase (2007a), the total amount of wastewater generated in this town is estimated to be about $1200 \mathrm{~m}^{3} / \mathrm{d}$ by the year 2025 . 
More than ever, the need for sustainable wastewater treatment system is becoming urgent and a matter of great concern for both public and local government. Thus, equipping small towns with improved and sustainable sanitation strategies is one of the keys toward sustainable development of small towns in Vietnam. In addition, the results of the interviews and informal talks with both public and local authorities reveals that the biggest concerns, which this town is facing, are how best to minimize the negative effects of the current effluent wastewater reuse practices in irrigation, and how to protect public health while at the same time obtaining the maximum benefits of nutrient recycling.

\subsection{Application of AHP technique for effective and successful sanitation planning in Toan Thang town}

\section{AHP techniques}

AHP (Saaty 1980; Saaty and Vargas 2001) is a powerful mathematical tool used to make decisions when multiple and conflicting objectives/criteria are present and when both qualitative and quantitative aspects of a decision need to be considered. This technique for multi-criteria decision making allows for consideration of both objective and subjective factors in determining the best alternative, and provides a ratio-scale ranking of alternatives (Tao and Hills 1999; Mollaghasemi and Pet-Edwards 1997; Saaty 1980). In this study, AHP is also used to explore how such a process can integrate and reconcile the interests and concerns of diverse stakeholder groups.

Normally, AHP is based on three principles: hierarchy construction, priority analysis, and consistency verification. In the first step, decision makers break down complex unstructured multiple criteria decision problems into component parts of which every possible attribute is arranged into multiple hierarchical structures. The second step consists of evaluating the alternatives and weighting the criteria. The alternatives are compared in pairs to assess their relative preference with respect to each of the criteria at the next higher level. Similarly, the criteria are compared in pairs to define their importance with respect to the goal. The verbal terms of the fundamental scale as proposed by Saaty $(1980,1996,2001,2004)$ are used to assess the intensity of preference between two elements. Using relative comparisons and verbal terms often facilitates the weighting of criteria as well as the evaluation of alternatives regarding non-quantifiable criteria. Once the verbal judgments are made, they are translated into numbers by means of the fundamental scale (Saaty 1980, 1996, 2001, 2004). For example, if two criteria are of equal importance, a value of 1 is given in the comparison; meanwhile, the number 9 indicates the absolute importance of one criterion over the other (Table 1). Each set of comparisons is then entered into a matrix, which is normalized to obtain the score for each element, i.e., the weights of the criteria and the criteria-specific priorities of the alternatives.

Table 1. Scale for pair wise assessment of preference and importance

\begin{tabular}{|l|l|}
\hline Numerical Scale & Verbal Scale \\
\hline 1 & Equal importance (preference) \\
\hline 3 & Moderate importance \\
\hline 5 & Strong importance \\
\hline 7 & Very strong importance \\
\hline 9 & Absolute importance \\
\hline $2,4,6$, and 8 & Intermediate values \\
\hline
\end{tabular}

Since the comparisons are carried out through personal or subjective judgments, some degree of inconsistency may occur. To guarantee the judgments are consistent, the final step of consistency verification, often regarded as an advantage of AHP, is incorporated to measure the degree of consistency among the pairwise comparisons by computing the consistency ratio (CR), which is calculated according to the equation:

$\mathrm{CR}=\mathrm{CI} / \mathrm{RI}$
where: $* \mathrm{CI}$ (Consistency Index) as a measure of the degree of inconsistency inthe matrix of joint membership judgements.

$$
\mathrm{CI}=\left(\left|\lambda_{\max }-\mathrm{N}\right|\right) /(\mathrm{N}-1)
$$

$\mathrm{N}$ : is the order of the matrix of the judgements

$\lambda_{\max }$ is the largest eigenvalue of the matrix of the judgements

* RI is a Random Consistency Index 
A panel of experts, decision makers, or stakeholders may be utilized in the application of AHP. Saaty (1996) recommends that the ratings from those experts and/or stakeholders may be accepted if the consistency ratio (CR) of the pairwise comparison matrix is less than or equal to 0.10 (i.e., $90 \%$ consistent or $10 \%$ inconsistent). Otherwise, it is recommended that the pairwise comparisons should be revised to improve the consistency. In practice, inconsistencies exceeding 0.10 occur frequently (Basetin 2007; Alpay and Yavuz 2009).

\section{Identification of stakeholder groups}

The stakeholders in the sanitation planning process can be classified into standard stakeholders and interest groups. Standard stakeholders are those who have legitimate responsibility to participate in the process. Standard stakeholders include the decision makers, experts, and planners and analysts responsible for preparing and managing the process (Lahdelma et al. 2000). Interest groups include political parties, civic organizations, or residents of the impact area. Each interest group has its own point of view for evaluating potential alternatives and often has different relational systems of preference (Roy and Vincke 1984; Bana e Costa 1988; Lahdelma et al. 2000), thus creating competition and conflicts on the basis of different group values (Lahdelma et al. 2000).

In this study, stakeholders are further devided into 3 groups. Stakeholder group 1 consists of sanitation scientists who work at universities and research institutes in Vietnam and engineers and consultants who work at environmental consulting companies involved in water and sanitation projects in small Vietnamese towns (SG1). Stakeholder group 2 (SG2) consists of sanitation planners and policy decision makers representing the government in formulating decisions for sanitation planning in small towns. Stakeholder group 3 (SG3) is composed of local town residents, farmers, and interest groups.

Only after viewpoints from all of these stakeholder groups are recognized, it is possible to identify the appropriate criteria and feasibility of each alternative to increase the probability of a successful sanitation planning process.

\section{Identification of short-listed strategies and impact categories (or criteria) for the assessment}

A broad range of factors was considered in the qualitative evaluation process for the selection a range of potential sustainable strategies prior to the selection of a short-listed strategies, including wastewater characteristics and standard for effluent discharge; social considerations; demand and use ( for example, total served population, population density, indoors or outdoors, centralized or decentralized, etc.); water availability (for waterborne systems); agriculture (potential for human excreta reuse); soil and topography (infiltration properties of the soil, and the direction of the groundwater flow); cultural aspects and practices around sanitation; climatic conditions (temperature, humidity, and rainfall); the investment, operation and maintenance $(\mathrm{O} \& \mathrm{M})$ costs; and the availability of technical skills for installation and O\&M. More importantly, a series of meetings with key stakeholder groups were held before conducting the main questionnaire surveys on preferences'assessment to gain consensus on priority strategies from a range of identified potential strategies.

A short-list of 3 strategies, from a wide range of potential strategies selected in the qualitative evaluation process, has been selected for further analysis and stakeholders' preferences assessment. These 3 strategies are selected based on all above factors as well as consultations with key stakeholders. Each strategy presents a solution for wastewater treatment and management system with a certain degree of trade-off between benefits and its associated impacts:

- Strategy 1: This represents "Business as usual strategy" where residents will continue with the existing wastewater system, no collection, and no centralized treatment facility. In this strategy, it is assumed that most households with the current simple type of toilets or latrines, such as single vault latrine or flushing toilet without septic tank, will all change to indoor septic tanks in the near future as a common trend during urbanization in Vietnam. As of 2009, over three-quarters of urban households in Vietnam rely on septic tanks; and this is expected to grow to an estimated 95 percent among urban dwellers and 60 percent among rural homeowners by the year 2015, due to the implementation of a 1999 policy that 
requires all households to use at least a septic tank (USAID 2010). In this strategy, it is assumed that effluents from these septic tanks are still discharged directly into water bodies in the surrounding areas.

- Strategy 2: This one represents a combined option between decentralized and centralized sanitation solutions, where all domestic wastewater will be treated in household septic tanks; effluent will be collected by a newly constructed wastewater collection network and centrally treated in a series of waste stabilization ponds including anaerobic ponds, facultative ponds, and maturation ponds. Effluent from waste stabilization ponds can be reused for agricultural fields.

- Strategy 3: This represents a decentralized sanitation solution, where a group of 25 or more households will be equipped with one communal baffled septic tank, sometimes referred to as an "advanced septic tank." Wastewater from each household will be collected by PVC piping network and then led to this common baffled septic tank for treatment before being discharged into surrounding water bodies. The baffled septic tank is an advanced type of conventional septic tank suitable for all kinds of wastewaters, including domestic wastewater. It has been proven that a baffled septic tank with or without anaerobic filter (BAST or BASTAF) is one of the most feasible decentralized sanitation options for wastewater treatment in residential areas of Vietnam (Anh et al. 2005). Its efficiency increases with higher organic load. Treatment performance is higher than with a conventional septic tank, being $65 \% 90 \%$ in terms of COD (70\%-95\% BOD) removal (Sasse 1998).

For sustainability and preferences assessment of each strategy, identifying a set of impact categories or assessment criteria is critical to eliciting the preferences of diverse stakeholder groups. The criteria should be reduced to a few key criteria, representing the major trade-offs involved in any empirical application of the model. From these considerations and discussion with key stakeholders through a series of interviews and questionnaire surveys, the following set of criteria has been identified, including organic emission loading, health impact due to global warming potential, potential for nutrient recovery and safe reuse, health impact due to local health risk, and cost of construction, operation, and maintenance.

\section{Construction of Decision Hierarchy}

Using the above information, the decision hierarchy has been structured as in figure 1. At the top is the overall objective of the decision as agreed upon by the stakeholders, that is, to select the most appropriate and sustainable wastewater treatment strategy for the study town. Level 2 consists of stakeholder groups. Three different stakeholder groups as described above are defined for this analysis. Level 3 presents the assessment criteria (also referred to as attributes) considered relevant for achieving the overall goal. At Level 4 , the three alternative treatment strategies are presented .

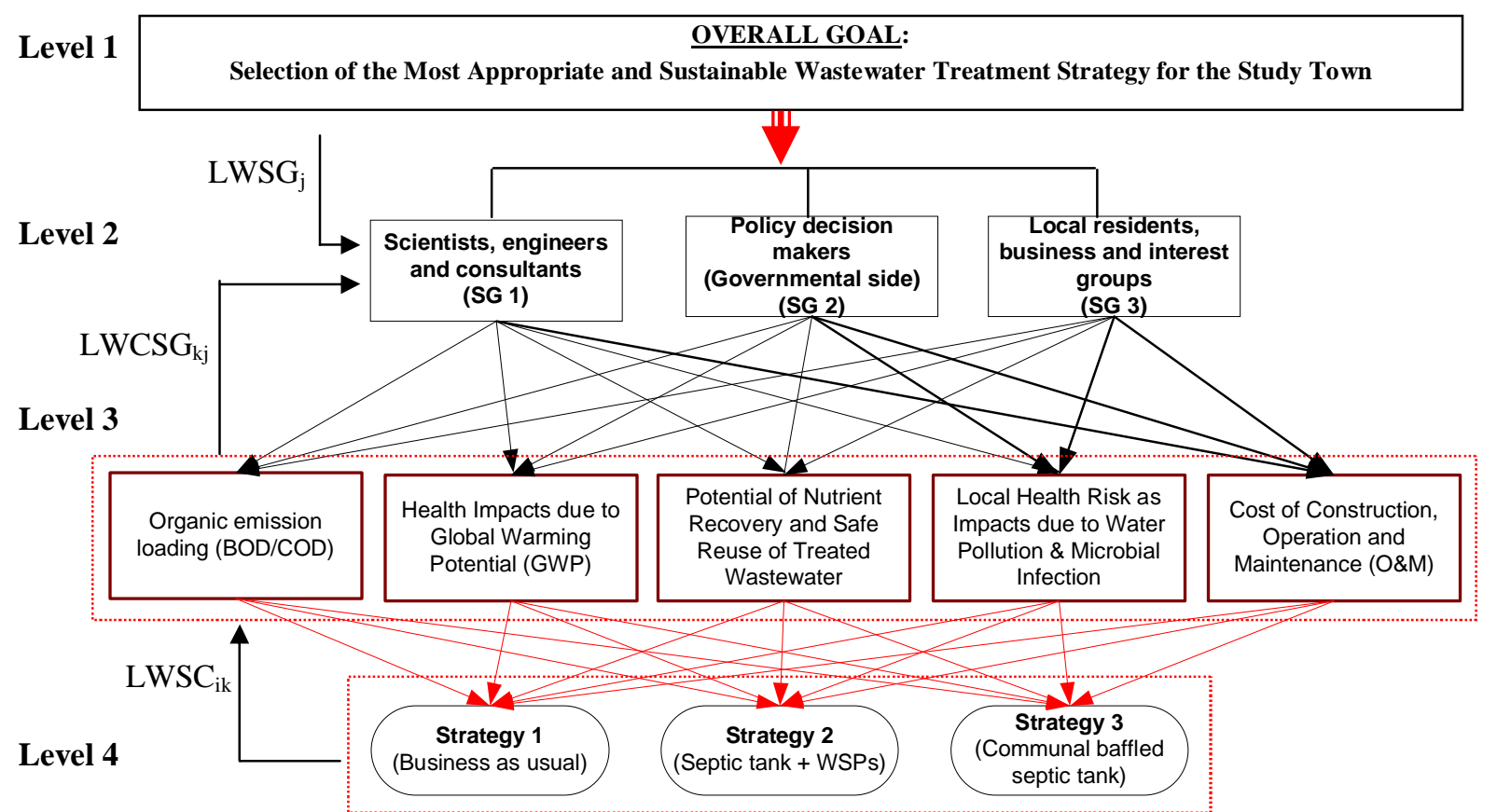

Figure 1. Hierarchical structure map of the decision process in selection of a sustainable wastewater treatment system 
A summary of the attributes for each strategy was based on the life cycle analysis, pollutant emission loads estimation, health damages analysis due to local water pollution and Global Warming Potential (GWP) from greenhouse gas (GHG) emissions, and cost analysis for each strategy was given to the respondents as reference information before their rankings. In this case study, the life cycle assessment (LCA) method has been used as a quantitative methodology to evaluate the side effects that proposed strategies have on the environment, with emphasis on GWP due to GHG emission over the entire period of the system's life cycle.

This information was used as valuable inputs, aimed at helping respondents in the questionnaire survey to elicit preferences with regard to a complex set of selected assessment criteria and strategies.

\section{Weighting and Ranking of Strategies}

Once the hierarchical structure map of the decision problem is constructed, the weights and preferences of various stakeholder groups should be determined. These three strategies were developed for cases of $(a)$ unequal weights for stakeholder groups and $(b)$ equal weights for all stakeholder groups. In case of unequal weights, weights could be obtained from stakeholder groups themselves through questionnaire surveys.

In order to resolve conflicting situations when combining the preferences from different stakeholder groups, the Global Weight (GW) concept is introduced. GW can be calculated by aggregating, as in Equation (1), the weight assigned by each stakeholder group to the strategies according to each criterion, the importance given to each criterion by each stakeholder group, and the share of each stakeholder group in the final decision schema (Kangas 1994).

$\mathrm{GW}_{\mathrm{i}}=\sum_{j=1}^{3}\left\{L W S G_{j}\left[\sum_{k=1}^{5} L W C S G_{k j}\left(L W S C_{i k}\right)\right\}\right.$

where $\mathrm{GW}_{\mathrm{i}}$ is the global weight of strategy $\mathrm{i}, \mathrm{LWSG}_{\mathrm{j}}$ is the local weight of stakeholder group $\mathrm{j}$, $\mathrm{LWCSG}_{\mathrm{kj}}$ is the local weight of the impact category $\mathrm{k}$ with respect to the stakeholder group $\mathrm{j}$, and LWSCik is the local weight of the strategy $\mathrm{i}$ with respect to the impact category $\mathrm{k}$.

Ranking of strategies may have different outcomes depending on the weight assigned among stakeholder groups and the given weight of each impact category.

\section{Results and Discussion}

\subsection{Questionnaire design and sampling sizes}

In order to understand the stakeholders' preferences toward the selected set of assessment criteria and strategies, questionnaire surveys and in-person interviews were conducted with three groups of stakeholders. The respondents were asked to rank the assessment criteria (attribute) according to its importance or priority by circling the appropriate strength of preference.

The questionnaire survey involved representative samples of 100 local households randomly sampled from 4 villages in Toan Thang town, 4 governmental policy decision makers and 5 from among sanitation scientists, engineers, and environmental consultants. Several studies have shown the independence of AHP relative to sample size (Kangas 1994; Soma 2003); and its application to this case should not be affected by the survey response rate and size.

\subsection{Stakeholders' preferences for treatment strategies based on impact categories and among impact categories themselves}

The results of questionnaire surveys conducted for the three different groups of stakeholders are utilized for understanding their preferences regarding selected impact categories and wastewater treatment strategies. Table 2 shows the local weight for impact categories assigned by each stakeholder group. Results revealed that all respondents found local health risk impact (D) was the most important impact category for choosing a wastewater treatment solution. The second most important category was potential for nutrient recovery and safe reuse of treated wastewater (C), followed by associated costs (E) of wastewater treatment strategies, and then organic emission loading (A). Health damage impact due to GWP (B) was assigned the lowest importance or priority among all proposed impact categories. 
Table 2. Local weights of impact categories from diverse stakeholder groups

\begin{tabular}{|c|c|c|c|c|c|}
\hline \multirow[b]{2}{*}{$\begin{array}{l}\text { Stakeholder } \\
\text { Group }\end{array}$} & \multicolumn{5}{|c|}{ Weights } \\
\hline & $\begin{array}{c}\text { Organic } \\
\text { emission } \\
\text { loading } \\
\text { (rank) }\end{array}$ & $\begin{array}{l}\text { Health impact } \\
\text { due to GWP } \\
\text { (rank) }\end{array}$ & $\begin{array}{l}\text { Potential of } \\
\text { nutrient } \\
\text { recovery and } \\
\text { safe reuse of } \\
\text { treated } \\
\text { wastewater } \\
\text { (rank) }\end{array}$ & $\begin{array}{l}\text { Local health } \\
\text { risk due to } \\
\text { water pollution } \\
\text { and microbial } \\
\text { infection } \\
\text { (rank) }\end{array}$ & $\begin{array}{c}\text { Construction and } \\
\text { O\&M cost }\end{array}$ \\
\hline $\begin{array}{l}\text { Scientists, engineers and } \\
\text { consultants }\end{array}$ & $0.169(4)$ & $0.049(5)$ & $0.225(2)$ & $0.333(1)$ & $0.224(3)$ \\
\hline $\begin{array}{l}\text { Policy decision makers } \\
\text { (Government) }\end{array}$ & $0.211(2)$ & $0.055(5)$ & $0.136(4)$ & $0.433(1)$ & $0.165(3)$ \\
\hline $\begin{array}{l}\text { Local residents, business and } \\
\text { interest groups }\end{array}$ & $0.095(5)$ & $0.169(3)$ & $0.231(2)$ & $0.375(1)$ & $0.131(5)$ \\
\hline
\end{tabular}

A possible explanation is that within the wastewater management sector, health damage impact due to GWP is minor compared to impacts from other categories; as a result, it has not been given priority or appropriate attention; and also those stakeholders who are responsible for the local environment concentrate more on local issues rather than GWP from wastewater treatment plants.

However, conflicts may arise in weighting and combining different stakeholder groups and impact categories. When one stakeholder group has a higher priority than the other groups, it will influence the final selection of the best strategy. In most practical situations, the preferences of the different stakeholder groups are not accorded equal consideration. Often the preferences of policy decision makers or sanitation planners may dominate and greatly affect the final rank of strategies. Thus, it is also important to consider the final rank of each strategy on the basis of the assumption that each group has an equal role in the process. Here, a weighting factor of 0.333 is applied to each of the groups' final preferences.

As shown in figure 2, local town residents assign Strategy 2 as the most preferred option with a weight of 0.203 , followed by Strategy 3 with a value of 0.084 and Strategy 1 with a value of 0.046 from a total of 0.333 , which corresponds to the assigned weight for each stakeholder group. In case of governmental sanitation planners, the highest priority was given to Strategy 2 with a weight of 0.213 , followed by Strategy 3 and Strategy 1 with weight values of 0.077 and 0.044 , respectively. For the scientists, engineers, and consultants group, most preferences were the same as those of stakeholder groups 2 and 3: preference was for Strategy 2, followed by Strategies 3 and 1 with weight values of $0.210,0.077$, and 0.045, respectively. In summary, these numbers reveal that the total weight assigned to Strategy 2 is the most preferred option with $62 \%$ of preferences in comparison with Strategy 3 with $24 \%$ and Strategy 1 with $14 \%$.

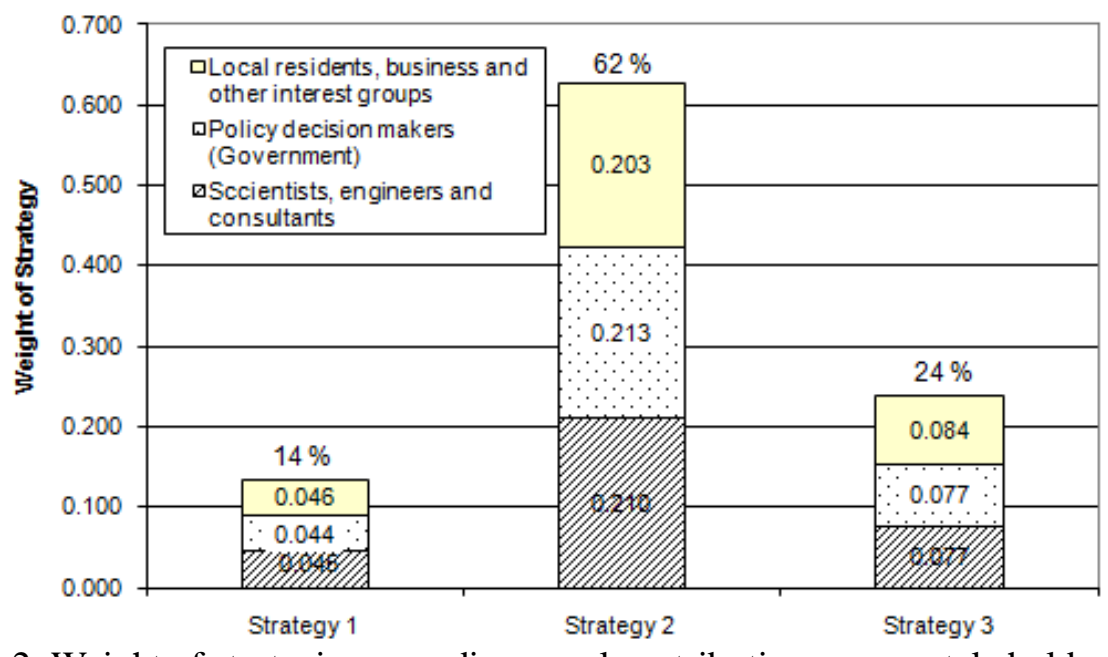

Figure 2. Weight of strategies according equal contribution among stakeholder groups 
The weight assigned to the impact categories and strategies varied among stakeholder groups. A closer look at each stakeholder group can provide a better understanding of their impact category preferences, which may have a significant effect on the final choice of strategies.

Table 3 shows the analysis for the impact categories and strategies from stakeholder group 1's points of view. According to survey results from stakeholder group 1, Strategy 2 is the most preferred option if looked at from the costs, local health risk, nutrient recovery and safe reuse of treated wastewater, and organic loading emission aspects. This strategy is followed by Strategy 3 and Strategy 1, respectively. However, if it is considered from the aspect of global health risk as loss of life expectancy due to GWP, Strategy 3 is considered the most preferred option, which is followed by Strategy 1. Strategy 2 is the least preferred option when considered from this aspect.

Table 3. Analysis for the impact categories and strategies from SG1's point of view

\begin{tabular}{|l|c|c|c|c|c|}
\hline $\begin{array}{l}\text { Selected } \\
\text { Strategy }\end{array}$ & $\begin{array}{c}\text { Organic loading } \\
\text { emissions }\end{array}$ & $\begin{array}{c}\text { Health risk due to } \\
\text { GWP }\end{array}$ & $\begin{array}{c}\text { Potential of } \\
\text { nutrient recovery } \\
\text { and safe reuse of } \\
\text { treated wastewater }\end{array}$ & $\begin{array}{c}\text { Local health risk } \\
\text { due to water } \\
\text { pollution and } \\
\text { microbial infection }\end{array}$ & $\begin{array}{c}\text { Construction and } \\
\text { O\&M cost }\end{array}$ \\
\hline Strategy 1 & 0.075 & 0.257 & 0.085 & 0.080 & 0.124 \\
\hline Strategy 2 & 0.708 & 0.223 & 0.758 & 0.758 & 0.511 \\
\hline Strategy 3 & 0.218 & 0.521 & 0.157 & 0.161 & 0.364 \\
\hline
\end{tabular}

Similarly, we have the analysis results for stakeholder 2 and stakeholder 3.

For stakeholder group 2, cost is given highest priority among impact categories. From the cost perspective, Strategy 3 is the preferred choice as this strategy offers a low-cost, flexible, and reliable solution. Its lower capital and O\&M costs make it an ideal system for small towns. Where a group of 25 households will share one communal baffled septic tank, as a result, investment and O\&M costs per household will be reduced significantly. Strategy 3 is ranked ahead of Strategy 1 and Strategy 2.

For stakeholder group 3, local health risk, nutrient recovery and safe reuse of treated wastewater, and global heath risk impact due to GWP are the dominant factors, preferred over costs and organic loading emissions. There are several reasons for such rankings. One of the possible reasons is that sanitation issues in general and wastewater treatment in particular are becoming urgent issues in the town under consideration. Therefore, according to the local town residents' opinion, they are very much concerned about not only their health but the health of future generations. Thus, local health risk, nutrient recovery and safe reuse of treated wastewater and global health risk are rated and given more priority than the other impact categories like organic emission loads and costs. Consequently, they then tend to choose the option that produces the lowest health risks in the short- and long-term. An impact from organic loading emission is considered the least preferred impact category when selecting the treatment strategies. This can be the result of poor understanding of the concept or impacts of organic loading emission (in terms of BOD/COD) although the interviewers have made great efforts to explain the concept compared with the time spent on other impact categories.

\subsection{Stakeholders' opinions on their priority and final ranking}

Analysis of the responses from stakeholder groups with respect to their roles on the final weighting scheme revealed that SG1 ranks their role as the most important in the final decision scheme with a weighting factor of 0.610 , equivalent to $61 \%$, and followed by SG3 and SG2 with weighing factors of 0.200 and 0.190 , equivalent to $20 \%$ and $19 \%$, respectively (Table 4).

Policy decision makers (SG2) rank local town residents' (SG3) role as the most important with a weighting factor of 0.701. Meanwhile, their role seems to be the least important with a weighting factor of 0.075 compared to 0.224 of scientists, engineers, and consultants' group (SG1). 
However, local town residents believe that the role of scientists, engineers, and consultants and their own role should be considered equal, accounting for a weighting factor of 0.375 or $37.5 \%$ of the final decision. The remaining 0.250 or $25 \%$ should be allotted to the contribution of the policy decision makers' role.

Table 4. Weight of the stakeholder groups with respect to the overall goal (read horizontally)

\begin{tabular}{|c|c|c|c|}
\hline Stakeholder Group & $\begin{array}{l}\text { Scientists, engineers and } \\
\text { consultants } \\
\text { (SG1) } \\
\text { (rank) }\end{array}$ & $\begin{array}{l}\text { Policy decision makers } \\
\text { (SG2) } \\
\text { (rank) }\end{array}$ & $\begin{array}{l}\text { Local town residents, } \\
\text { business and interest } \\
\text { groups } \\
\text { (SG3) } \\
\text { (rank) }\end{array}$ \\
\hline $\begin{array}{l}\text { Sanitation scientists, engineers } \\
\text { consultants (SG1) }\end{array}$ & $0.610(1)$ & $0.190(3)$ & $0.200(2)$ \\
\hline $\begin{array}{l}\text { Policy decision makers representing for } \\
\text { Governmental side (SG2) }\end{array}$ & $0.224(2)$ & $0.075(3)$ & $0.701(1)$ \\
\hline $\begin{array}{l}\text { Local town residents, business and interest } \\
\text { groups (SG3) }\end{array}$ & $0.375(1)$ & $0.250(2)$ & $0.375(1)$ \\
\hline
\end{tabular}

Considering the above results, the final weights have been calculated for each strategy on the basis of different stakeholder groups' points of view using the Global Weight equation (1). Sensitivity analysis showed that the strategy preference would not change across the stakeholder groups if the weighting factors assigned to different groups changed; although the weight values assigned for each strategy varied among different groups (Fig. 3). This information can be used to determine the acceptability of the strategies and the priorities given for different impact categories.

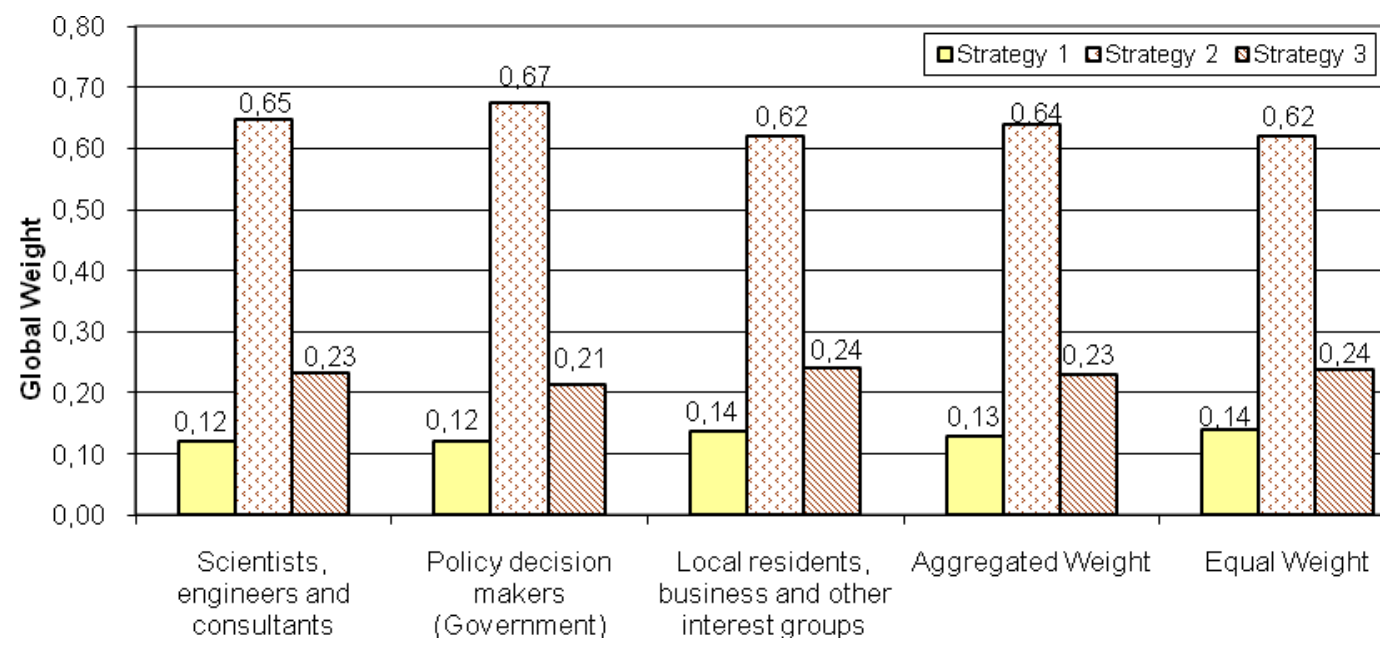

Figure 3. Sensibility analysis of weighting scheme strategies (Global Weight)

In summary, the analysis results from the trade-off considerations and stakeholders' preferences assessment showed that Strategy 2 is ranked as the first priority by all stakeholder groups with $64 \%$ support compared with Strategy 1 and Strategy 3, which had 13\% and 23\%, respectively. Thus, Strategy 2 seems to be the most promising and sustainable choice for the town as it brings acceptably positive impacts with regard to the environmental, socio-economic, health, technical and functional aspects including low capital, O\&M costs; resulting in low user costs, high treatment efficiency, possibility for nutrient recovery and safe reuse of treated wastewater, and it especially minimizes the health risk from effluents to which local town residents may be exposed.

\section{Conclusions and Recommendations}

This case study has indicated that the design and selection of any wastewater treatment and management system should be integrated into community needs. Moreover, the public's understanding of trade-offs is critical in gaining public support for long-term sustainability of the solution.

A combination of several decision support tools in this case study including LCA, a set of multi-dimensional criteria, and AHP has formed a powerful and proven methodology for the decision-making process, especially for granting stakeholders valuable insights into technical as well as sustainability aspects for each 
proposed strategy. As a result, it leads to a better understanding and consensus among the stakeholders of decision-making groups so that they are likely to become more committed to the selected alternatives.

In a real-world situation, this proposed approach is particularly useful for resolving conflicts in the sanitation planning process, and it can be successfully used by a certain interest group or can be applied through a group decision process.

\section{References}

Alpay, S., and Yavuz, M. (2009). Underground mining method selection by decision making tools. Tunnelling and Underground Space Technology, 24 (2), 173-184.

Anh, V. N., Nga, P.T., Nhue, T.H., and Antoine, M. (2005). Potential Decentralized Wastewater Management for Sustainable Development from Vietnamese Experience. In: Proceedings of the Water Environmental Federation (WEF) International Conference: Technology San Francisco, CA, USA, 917946.

Bana e Costa, C. A. (1988). A methodology for sensitivity analysis in three-criteria problems: A case study in municipal management. European Journal of Operational Research, 33, 159-173.

Bascetin, A. (2007). A decision support system using analytical hierarchy process (AHP) for the optimal environmental reclamation of an open-pit mine. Environmental Geology, 52(4), 663-672.

Herath, G. (2004). Incorporating community objectives in improved wetland management: The use of analytical hierarchical process. Journal of Environmental Management, 70, 263-273.

Kangas, J. (1994). An approach to public participation in strategic forest management planning. Forest Ecology and Management, 70, 74-88.

Lahdelma, R., Salminen, P., and Hokkanen, J. (2000). Using multicriteria methods in environmental planning and management. Environmental Management, 26(6), 595-605.

Liu, D., Bishu, R.R., and Najjar, L. (2005). Using the analytical hierarchy process as a tool for assessing service quality. IEMS, 4(2), 129-135.

Mariño, M., and Boland, J. (1999). An Integrated Approach to Wastewater Treatment. Deciding Where, When, and How Much to Invest. World Bank, Washington D.C.

Mollaghasemi, M., and Pet-Edwards, J. (1997). Technical Briefing: Making multiple-objective decisions. IEEE Computer Society. Los Alamitos.

Roy, B., and Vincke, P. (1984). Relational systems of preference with one or more pseudocriteria: Some new concepts and results. Management Science, 30(11), 1323-1335.

Saaty, T. L. (1980). The Analytic Hierarchy Process. McGraw-Hill, New York, NY.

Saaty, T.L. (1996). Multicriteria Decision Making: The Analytic Hierarchy Process. AHP Series, Pittsburgh, PA: RWS Publications

Saaty, T.L., and Vargas, L.G. (2001). Models, Methods, Concepts \& Applications of the Analytic Hierarchy Process. Klumer Academic Publishers.

Saaty, T.L. ( 2004). Decision making-The analytic hierarchy and network processes (AHP/ANP). Journal of Systems Science and Systems Engineering, 13(1), 1-35.

Sasse, L. (1998). DEWATS_Decentralized Wastewater Treatment in Developing Countries, Delhi 1998.

Soma, K.. (2003). How to involve stakeholders in fisheries management: A country case study in Trinidad and Tobago. Marine Policy, 27(1), 47-58.

Staykova, C., Kingdom, B. (2006). Water Supply and Sanitation Strategy—Building on a Solid Foundation. World Bank - Office in Vietnam.

Tao, Y. X., and Hills, P. (1999). Assessment of alternative wastewater treatment approaches in Guangzhou, China. Water Science and Technology, 39(5), 227-234.

USAID. (2010). A Rapid Assessment of Septage Management in Asia: Policies and Practices in India, Indonesia, Malaysia, the Philippines, Sri Lanka, Thailand, and Vietnam. AECOM International Development, Inc. and the Department of Water and Sanitation in Developing Countries (Sandec) at the Swiss Federal Institute of Aquatic Science and Technology (Eawag)

Viwase. (2007a). Options Report-Water Supply, Sewerage and Environmental Sanitation Project for Toan Thang Town, Hung Yen Province, Vietnam. Water Supply and Sanitation Programme for Towns in Vietnam, Ministry of Construction, Vietnam. (in Vietnamese) 
Viwase. (2007b). Report on Socio-Economic Survey in Toan Thang Town - Kim Dong District - Hung Yen Province. Water and Sanitation Programme for Small Towns in Vietnam, Ministry of Construction.

WHO. (2006). Guidelines for the Safe Use of Wastewater, Excreta and Greywater. Volume 2: Wastewater Use in Agriculture. World Health Organization, Geneva, Switzerland. 